\title{
Groba, Xavier (2019): Antonio Fraguas e a memoria musical de Cotobade, Compostela: aCentral Folque, Centro Galego de Música Popular (Colección Chave Mestra), 225 pp. + cedé.
}

Los dieciocho libros + cedé que han visto ya la luz en la Colección Chave Mestra, que edita aCentral Folque, Centro Galego de Música Popular, que dirige Ramón Pinheiro, son los frutos de una de las aventuras más originales, arriesgadas, necesarias, entre las que están siendo llevadas a la palestra nacional e internacional de la recuperación de la cultura tradicional, o del patrimonio inmaterial, si se prefiere. Y no solo en el ámbito de la música popular gallega, que es el campo de acción que declaran como prioritario pero no exclusivo quienes impulsan aCentral Folque y Chave Mestra, sino también en el de la literatura y la historia oral, la danza, la fotografía, la religiosidad, los oficios, las artesanías y tecnologías, las fiestas, las mentalidades, la etnografía, la sociología, la arquitectura, el paisaje...

Ninguna de esas dimensiones se echa en falta en los grandes frescos de la vida del pasado que intentan reconstruir, desde presentes que quedan también detalladamente (auto)retratados y (auto)justificados, cada uno de los libros-cedés de la Colección Chave Mestra. No hay forma de discurso, estrato, contexto, acepción que queden relegados a un injusto segundo nivel, ni desdeñados de primeras: cada pálpito de memoria sustraído a la mancha del olvido es recuperado con pulcritud arqueológica, valorado en su justa medida y engastado en el lugar preciso del collage reconstruido y casi animado que nos regala cada una de estas producciones. Las cuales son siempre complementadas, para mejor cumplir con su afán panóptico, con la crónica de cómo cada investigador-exploradorautor de cada libro-cedé logró aproximarse, en desvelos de años y que rozaron no pocas veces el suspense detectivesco, a los sujetos y a los objetos de sus pesquisas.

No conozco, en fin, ninguna iniciativa que se pueda medir con esta en cuanto a método, coherencia, sistematicidad, resultados y cuidado artístico (porque cada libro-cedé se beneficia de una presentación editorial deslumbrante), ni en España ni en el mundo hispánico; y no tantas serán equiparables, sospecho, en el resto del mundo.

En la portada de la sensacional monografía, última hasta ahora de la Colección Chave Mestra, que el etnomusicólogo Xavier Groba ha consagrado a la recuperación de los trabajos y de la memoria del folclorista Antonio Fraguas Fraguas (nacido en la parroquia de Loureiro, en el municipio de Cotobade, Pontevedra, en 1905, y muerto en Santiago de Compostela en 1999) deslumbra, para empezar, la fotografía de un «baile con discos de gramófono na Casa da Cancheta. Igrexario, Loureiro. Anos 30», procedente del archivo de Anxo Méndez. Deslumbra no solo porque se trata de una fotografía de enorme valor documental, artística y técnicamente muy lograda, que no puede menos que suscitar fascinación instantánea, y que para sí quisieran muchas portadas de catálogos de grandes museos y de libros notables. También porque nos traslada un síntoma agudo, con ese gramófono a primera vista extemporáneo dominando el paisaje de un baile de aldea y desplazando a los músicos de toda la vida, de una época, la de la primera expansión por el mundo rural de las máquinas reproductoras del sonido, de grietas y realineamientos cruciales en los contornos y los equilibrios internos de la cultura tradicional. 
La elección como tarjeta de presentación del libro de esa notable fotografía, captada en un rincón del remoto municipio gallego en el que Fraguas nació y desarrolló su labor de folclorista, y trabajosamente localizada, como todas las demás, por Groba, es aviso de que este título, como los demás de su colección, busca ante todo situar a alguien (aquí, a un etnógrafo convertido ya en historia; en otros libros-cedé, a algún artista notable de la música o de la palabra tradicional) dentro de un paradigma polifónico y polifacético, en que el paisaje y la tradición iluminen o expliquen a la persona, y viceversa. No se espere, pues, un libro-cedé acerca del folclorista Antonio Fraguas, sino un trabajo con múltiples enfoques y asedios del tiempo, el lugar y las circunstancias que configuraron su biografía, sus obras, su legado.

Ello contribuye a explicar la paradoja de que el método y el libro-cedé de Groba sean mucho más adelantados y sofisticados de lo que fue el folclorismo muy vocacional y entusiasta, pero técnicamente poco innovador, convencional incluso, del propio Fraguas. Las limitaciones del método del folclorista de Cotobade eran inevitables, dadas las poco estimulantes circunstancias en que desarrolló su vocación. Fraguas fue una persona fiel siempre a su compromiso para con su tierra y su cultura, rebosante desde su juventud de inquietudes, proclive a implicarse en los trabajos de grupos y asociaciones culturales y a colaborar con músicos, etnógrafos, museógrafos. Pero su formación autodidacta (el folclore no existía como especialización en la universidad de su tiempo), la parquedad de sus medios (entonces era muy raro que se trabajase con grabadora de sonido, o con cámara fotográfica o de cine: el lápiz y el cuaderno fueron sus útiles exclusivos), sus no muchas salidas de Galicia, la imposibilidad de acceso o de contacto con corrientes disciplinares avanzadas y con bibliografías especializadas y actualizadas, determinaron que su método fuese más propio de un intelectual de la primera mitad del siglo XX que de uno de la segunda mitad.

En su tiempo suponía ya una enorme conquista que un aldeano como él, hijo de una labradora y de un cantero, pudiese hacer sus estudios medios en Pontevedra y licenciarse en Letras en la Universidad de Santiago, y más todavía que llegase a obtener una cátedra de instituto y que fundase una academia en la que se vio obligado a ejercer en los largos años en que el franquismo le hizo víctima de represalias y confiscó su plaza de funcionario, en castigo por su juvenil vinculación con el galleguismo histórico del Seminario de Estudos Galegos; Fraguas llegó, por cierto, a doctorarse, en Madrid en 1948: ahí tocó el techo académico al que le fue permitido llegar.

Su Cantigueiro de Cotobade publicado en 1998, muy al final de su vida, como ampliación de las Aportacions ó Cantigueiro de Cotobade de 1985, es un libro revelador de su forma de hacer: tiene un prólogo muy escueto, de tan solo ocho páginas, que nos traslada muy pocas de las informaciones que hubiesen sido precisas para poder entender más cabalmente, desde sus contextos sociales y rituales, el corpus de versos que despliega ante nuestros ojos. Viene después la edición de 1110 composiciones (en la versión de 1985 eran 992), la gran mayoría cuartetas, organizadas no por temas ni por ocasiones o contextos rituales, sino por un orden alfabético expeditivo y poco matizado, del que solo se apartan las once últimas letras, que son un cajón de sastre en que se mezcla alguna dote burlesca con algún parrafeo, y alguna canción narrativa con algún romance. Ningún canto lleva indicación del enclave exacto en que fue anotado, ni de quién lo comunicó, ni de las ocasiones y contextos en que se producía. Por Groba sabemos, en fin, que muchas de las canciones que Fraguas anotó en su municipio, en castellano la mayoría, pero algunas también en gallego, quedaron descartadas y no llegaron a ver la luz. 
Duele pensar en las razones ambientales que presionaron para que no pudiese volar más alto un cancionero elaborado por un investigador con el conocimiento nativo del terreno y con los enormes entusiasmo, compromiso y curiosidad intelectual que adornaron a Fraguas. Pesaron sin duda el entorno sociopolítico, que (en los años sobre todo de la dictadura) estigmatizaba la lengua y la literatura tradicional en gallego; el desprecio o la indiferencia del búnker universitario hacia toda labor folclorística que no se centrase en la recuperación del romancero que abanderaba desde Madrid don Ramón Menéndez Pidal, lo que tuvo como consecuencia que gran parte de la etnografía gallega y española del siglo XX estuviese en mano de aficionados (algunos muy valiosos y preparados, otros menos) a los que casi siempre les fueron negados los medios y los reconocimientos; el casi total aislamiento con respecto a las nuevas ideas y métodos que iban surgiendo en los estudios de folclorística de más allá de nuestras fronteras; y, por supuesto, las dificultades para publicar, que eran muchísimas. Es de presumir que si Fraguas hubiese contado con los medios técnicos (con grabadoras de sonido y de imagen, y con cámaras fotográficas, por ejemplo) y con los modelos de trabajo, las bibliografías, las redes de contactos e intercambios académicos, los horizontes editoriales mucho más amplios y variados de hoy, su producción hubiese sido considerablemente más extensa, profunda, sofisticada.

Cosa bien distinta es, claro, que el significado y el valor de los materiales literarios (porque todo el complejo cultural atestiguado por Fraguas en las aldeas de Cotobade quedó reducido a pura letra escrita-transcrita) sea, conforme es, excepcionalmente valioso e interesante. Su Cantigueiro de Cotobade es, con todas sus limitaciones, uno de los más importantes de los que han sido compilados en Galicia, y uno de los que más abundan en joyas literarias de mérito inaudito. El repertorio, por ejemplo, de los cantos de canteros y de arrieros es sensacional, por más que de su significado y de su importancia nos prevenga mejor Groba, con los subrayados y la documentación adicional que aporta, que el propio Fraguas.

El libro de Xavier Groba, Antonio Fraguas e a memoria musical de Cotobade, suelto, inventivo, lleno de colores y de quiebros, se toma la libertad de comenzar por el final: por una muy reciente entrevista a Manuel Rodríguez Vidal y Pilar Rodríguez Pérez, realizada por el propio Groba. Pilar, pianista, profesora, elaboró en 2004 un originalísimo trabajo académico que consistió en grabar en los mismos escenarios de Cotobade en que trabajó Fraguas, y en editar y estudiar, un corpus de cuarenta y dos variantes de las canciones que el viejo folclorista, que había fallecido cinco años antes, había anotado en vida. Colaboró en aquel trabajo, e intervino también en la entrevista con Groba, Manuel, el padre de Pilar, quien había sido vecino de Fraguas. Una entrevista no menos reveladora, que Groba inserta en el corazón del libro, es la que hizo en 2019 al casi nonagenario pianista y conocido empresario compostelano Ramón Castromil Ventureira, quien fuera amigo y colaborador bastante regular de Fraguas.

Viene a continuación una «Aproximación á Terra de Cotobade» y una rememoración de los pasos que algunos folcloristas precursores dieron por ella. Hay recuerdo incluso para el ilustre e inconformista fray Martín Sarmiento, quien tenía vínculos familiares con Cerdedo y Aguasantas. Se pasa luego a la revisión minuciosa de una abigarrada nómina de folcloristas voluntariosos, aficionados e irregulares que prepararon el camino de dos investigadores de mayor peso: Casto Sampedro Folgar (1848-1937), quien anotó en Cotobade once temas lírico-musicales como mínimo, y Saturnino Cuíñas Lois (18971978), sacerdote, buen cantor y buen tañedor de zanfona, quien trabajó regularmente con el músico Adolfo Anta Seoane (1900-1978), el cual rellenaba las partituras a partir de las 
canciones que don Saturnino le cantaba tras aprenderlas de oído; diez temas musicales de Cuíñas Lois son representativos de la tradición de Cotobade.

Sigue una detallada biografía del propio Fraguas, en la que Groba subraya lo humilde de sus orígenes, la pasión que desde su juventud sintió por la cultura gallega y por su recuperación y reivindicación, las penalidades que por intransigencias políticas sufrió, los trabajos que hizo y los cargos que ocupó en una gran cantidad de asociaciones e instituciones gallegas, y las distinciones que le llegaron en las últimas décadas de su vida, entre ellas la de Cronista Xeral de Galicia. Aunque lo más interesante de esta sección del libro es sin duda la indagación en los métodos, los intereses, los logros y las decepciones del biografiado, del que aprendemos que fue también arqueólogo aficionado, que le interesaban los fuegos artificiales y los toques de campanas, y que hizo trabajo de archivo en legajos de parroquias y administraciones, en los que exhumó documentos de gran interés. Véase por ejemplo, en las páginas 73 y 131 del libro de Groba, la interesantísima imprecación contra las «yladas de noche» de las mujeres aldeanas de Cotobade, que Fraguas localizó en el remoto «Libro II fabrica de la iglesia de Janza» y publicó en un gran artículo sobre «Fiestas populares de Galicia. Fiadeiros» que vio la luz en 1949.

Fraguas anotó además relatos en prosa, en especial si tenían que ver con la música y con el baile popular. En la p. 76 del libro de Groba se puede leer una versión excelente de una leyenda internacional que ha sido minuciosamente estudiada en Carrascosa (2019). Otra de las aportaciones más relevantes del libro de Groba es la presentación, íntegra y en suntuosa reproducción fotográfica, del «Cancioneiro inédito de Cantos de Nadal, Xaneiras e Reis de Cotobade elaborado por Fraguas e os seus colaboradores musicais, 1947. Fondo Antonio Fraguas do Museo do Pobo Galego»».

Son evaluadas a continuación las labores de los folcloristas que pasaron por Cotobade entre las décadas de 1950 y 1980: Alan Lomax, Manuel García Matos, Gustav Henningsen, Manuel Garrido Palacios... Y sigue un largo etcétera, en el que abundan los nombres de asociaciones culturales y de colectivos folclóricos, que han estado registrando cantos populares en el municipio en las décadas últimas; destacan las generosas y desinteresadas colaboraciones de parte de la mejor investigación etnomusical gallega de las últimas décadas: María Vidal, Pichi Abollado, Luís Prego o Guillerme Ignacio Costa.

De toda esta agotadora indagación ha logrado deducir Groba hasta 371 piezas musicales, en formato de partitura, de registro sonoro o de registro audiovisual, y ha seleccionado las que le han parecido mejores y más representativas hasta colmar las 43 pistas del cedé que con sus sones acompaña a su libro.

Ello nos permite la escucha de un tesoro inimaginable de cantos de arrieros y de canteros, de cuna, burlescos, de juegos, de rúas o veladas nocturnas (que incluyen cantos de llamada, jotas, ribeiranas, valses, mazurcas, danzas, pasodobles, romances), cantos de desafío, de Navidad, de Reyes y de aguinaldo. Se cierra el cedé con el sonido sacado del «asubío de pedra de Antón Fraguas», un rudimentario instrumento musical que el folclorista rescató un yacimiento arqueológico; y a continuación con una marcha procesional. No son estos que escuchamos nosotros, por desgracia, los mismos cantos que escuchase y que no tuvo oportunidad de grabar Fraguas, pero es de presumir que sonasen muy parecidos a aquellos, puesto que la línea del lugar, de la tradición y de la memoria no llegó a quebrarse del todo.

Groba vuelve a desbordar la pura letra firmada por Fraguas con sus eruditísimos comentarios, algunos de los cuales se convierten en monografías de alto nivel, acerca de los brindis y las cencerradas (pp. 110-115), los rituales de la rúa, ruada, fiadeiro o serán (pp. 115-132), los cantos de trabajo, labores agrícolas, esfolladas, cavadas o cachadas 
y ferias (pp. 132-136), los cantos de Navidad, carnaval, cuaresma, Semana Santa (pp. 136-150), o los de las fiestas parroquiales y romerías (pp. 151-162). Se explaya también, sobre la pauta de Fraguas pero yendo más allá, acerca del arte de los campaneros, de los ciegos músicos, de los inventores de instrumentos insólitos (como la extravagante vocalina diseñada por un paisano de Cotobade y que no llegó a comercializarse), o de los gaiteros y acordeonistas, a los que dedica un capítulo monumental (pp. 171-197). El libro remata con una profusa bibliografía, con diecinueve partituras musicales de José Luís do Pico Orjais y por varios bailegramas de Sergio Cobos.

Se hace evidente, al concluir su lectura y su audición, que este libro-cedé no aspira a ser una monografía definitiva, sino una invitación a dar continuidad a la pesquisa. Lo ideal sería que ahora, sobre un terreno tan ejemplarmente desbrozado, fuesen dados a conocer los apuntes de campo, los trabajos inéditos y las composiciones y páginas de Fraguas que quedaron descartadas o en la sombra, y que se hallan en el legado que el folclorista dejó en el Museo do Pobo Galego; y que fuesen reunidos, en uno o en varios volúmenes, sus artículos y monografías dispersos, de los que cabe esperar que, vistos en conjunto, obliguen a una reevaluación radical y muy positiva de su figura; y, puestos a pedir, que se volviese a editar, pero de manera crítica, su hermoso Cantigueiro de Cotobade; y hasta que pudiese alguna vez ver la luz una etnografía general de Cotobade, con las contribuciones de todos los folcloristas mayores y menores que han quedado dilucidados, con claridad pero también muy en síntesis, en estas páginas.

Si algún día todos esos sueños se acercan a la realidad, y con la calidad, la elegancia artística y la perfección técnica con que ha sido confeccionado este libro-cedé, podrá decirse que se habrá hecho justicia a la figura y al legado de Antonio Fraguas, y a la singular cultura tradicional de su solar de Cotobade.

\section{EstUdios CITADOS}

Carrascosa, Cruz (2019): «Bailar con el diablo: metamorfosis de una leyenda oral, del Abruzzo italiano a la literatura de cordel de Brasil», Boletín de literatura oral, 9, pp. 91-120. DOI: https://doi.org/10.17561/blo.v9.5

José Manuel Pedrosa

Universidad de Alcalá

$$
\text { j }
$$

